\title{
Block-box structures load-bearing capacity under special loads
}

\author{
Marat Salakhutdinov*1[0000-0002-9452-0271], and Kamil Khalilov ${ }^{1}$ \\ ${ }^{1}$ Kazan State University of Architecture and Engineering, 420043 Kazan, Russia
}

\begin{abstract}
Block-box structures today are widely used in construction. Their main features are mobility, lightness and the possibility of assembling block-boxes for any technological purpose. Block-boxes are used in the arrangement of oil and gas fields, settlements and cities where it is necessary to carry out construction in a short period of time or where there is no industrial infrastructure. When designing, it is often necessary to take into account special loads (earthquake or explosive), which significantly affect the applied structural solutions. In this paper, the load-bearing steel structures of block-boxes of various configurations and sizes under the influence of special types of loads are considered. Numerical research, analysis and improvement of structural solutions are carried out.
\end{abstract}

Keywords. Block-box structures, finite element method, special types of loads, structural design, earthquake, blast waves.

\section{Introduction}

The growing demand for prefabricated buildings and structures causes the relevance of research and development in the field of their design, improvement of structural materials, construction and operation [1-7]. For example, block-boxes have a wide variety of applications, configurations, as well as constructive form. The experience of using block boxes, examples of successful implementation, their advantages and disadvantages are shown in [8-11]. They are used for deployment of technological equipment and pipelines, as control rooms, as well as other rooms with permanent or temporary stay of people. The main load-bearing element is a steel frame. The frame includes base elements (reinforced floor), columns, beams, ties. The types of block boxes are shown in Fig. 1.

At industrial facilities related with the use of flammable gases and liquids, in emergency situations, nearby buildings and structures may perceive special dynamic effects [12]. They arise as a result of explosions of gas-vapour mixtures (GVM). Such explosions are characterized by high intensity, which depends on the chemical composition of the mixture and the distance to the explosion, the duration of action, which coincides with the period of natural oscillations of the structural elements of the building [13-17]. The impact of the explosion also depends on the location of the explosion source in relation to the building. External and internal explosions are different. In this case, the external impact of a physical explosion is considered.

${ }^{*}$ Corresponding author: lider-kazann@yandex.ru 

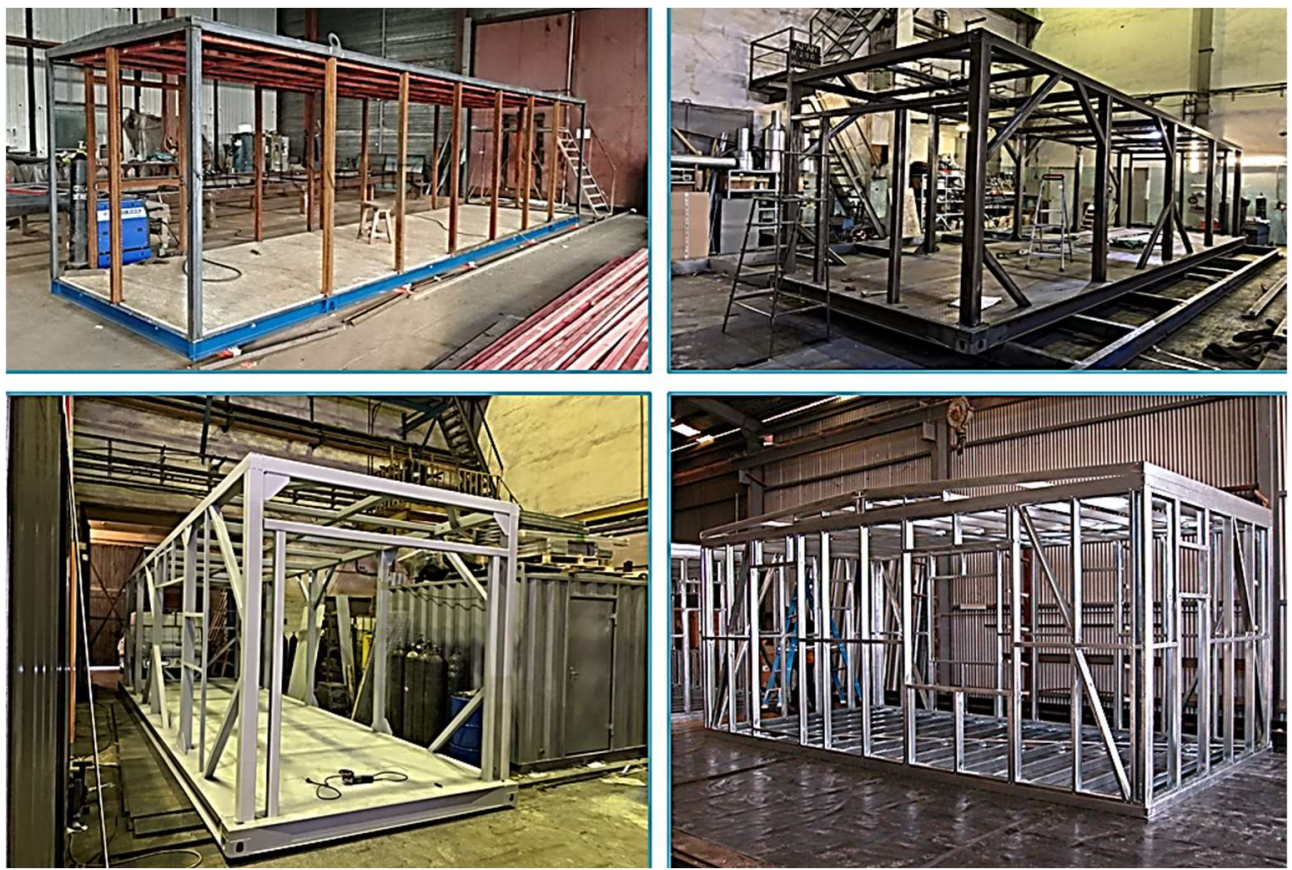

Fig. 1. Enclosure-boxes (block-boxes).

Also, in some parts of Russia, there is a danger of seismic action. An earthquake is an unpredictable natural disaster that affects buildings by vibrating the earth's surface $[18,19]$. In addition, in places where oil and gas fields are developed, subsidence of the earth's surface often occurs, which in turn can activate an earthquake in seismic regions. In this case, the impact on the supporting structures depends not only on the strength of the seismic effect, but also on the nature of the force effect of the soil on the structure.

Due to the rather wide application of block-boxes [20,21], it is often necessary to calculate them for special types of loads. The statistics of the number of accidents by their types at facilities in the oil and gas industry for 2003-2017 is represented on the Fig. 2.

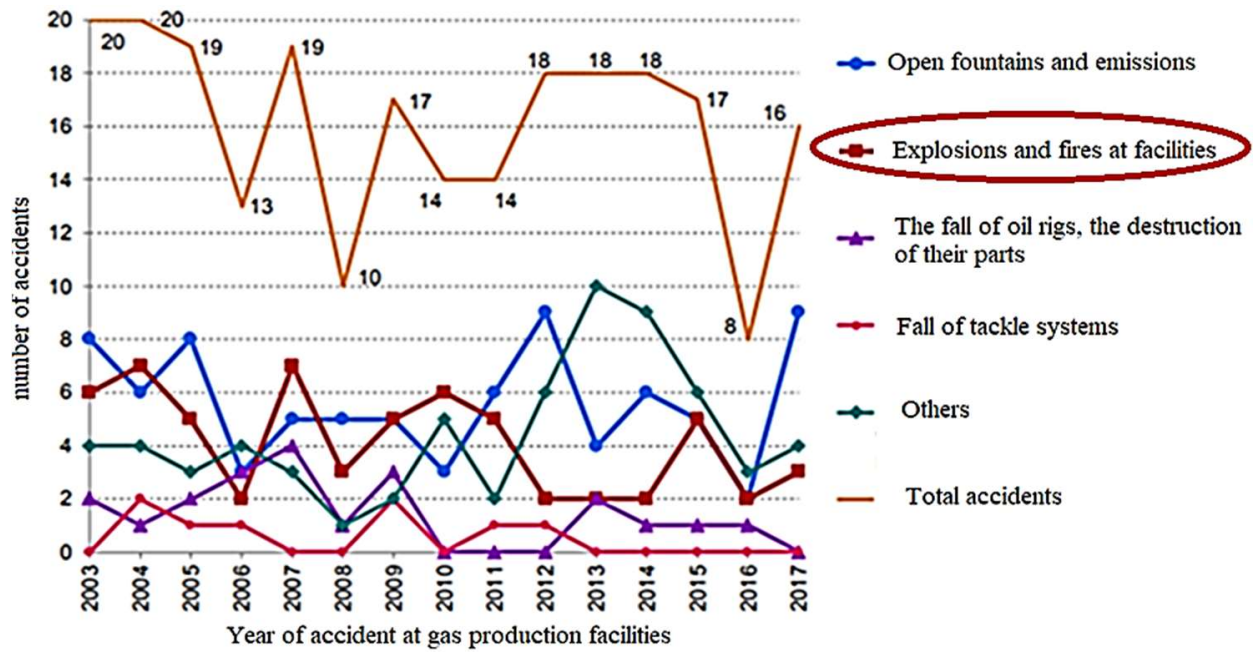

Fig. 2. Accident statistics at oil and gas production facilities [22]. 
Despite the fact that explosions and fires do not happen so often, they, nevertheless, occupy the third place among all possible accidents. Therefore, the installation of blockboxes in the seismic parts of the country, close to the places where wells are drilled and the work with highly flammable liquids exists, doesn't make it possible to ignore these loads.

In this work a technological block (block-box) [23] is considered, where the main attention is paid to special loads, which have a great impact on the steel spread of a structure, sometimes significantly increasing its general weight and cost. The research results of the bearing capacity of block-box structures for each type of load, reinforcement options presented in different conditions and then a comparative analysis is carried out.

The purpose of this article is to study the bearing capacity of block-boxes under special loads, to find the most effective ways of reinforcing and calculate the steel spread and the general weight of the structures.

\section{Methods}

The block-box is a structurally complete and spatially formed assembly unit made of steel profiles of different sections. Articles [24-27] consider the issues of calculation and design of load-bearing elements of block-boxes. As an example, a three-dimensional model was built and calculated by the finite element method in the LIRA-SAPR software package. The load summary on the structure was carried out in accordance with the construction code SP 20.13330.

For the calculation, a block-box with dimensions of $8.5 \times 3.3 \mathrm{~m}$ in plan and $3.0 \mathrm{~m}$ height was adopted. The columns are spaced with a step of $2.125 \mathrm{~m}$ apart in the longitudinal direction, and with a step of $3.3 \mathrm{~m}$ in the cross direction. The span of longitudinal beams is $1.06 \mathrm{~m}$. The bottom of the structure is made of longitudinal and cross elements (Fig. 3).

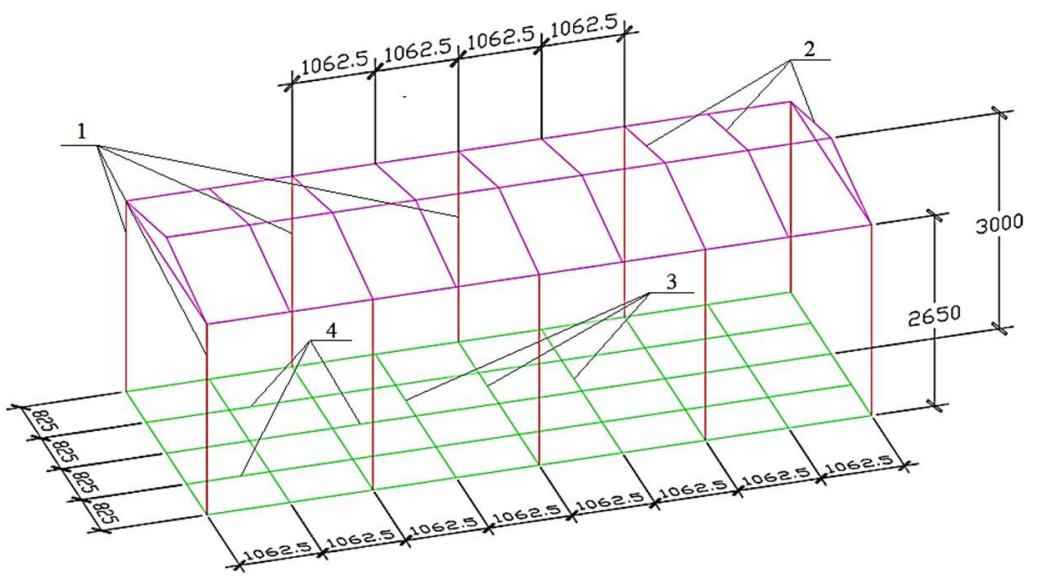

Fig. 3. General view of the technological block-box: 1 - columns; 2 - longitudinal beams; 3 - cross elements of the bottom; 4 - longitudinal elements of the bottom.

In this paper, 3 load cases are reviewed. The first one includes only the main combination (permanent and temporary loads without taking into account special loads). The second one includes the main combination and explosive impact. The third one includes the main combination and seismic action.

\section{$2.11^{\text {st }}$ load case}

The structure is loaded by dead load, the load from the equipment $\left(3.75 \mathrm{kN} / \mathrm{m}^{2}\right)$ and live load $\left(2.4 \mathrm{kN} / \mathrm{m}^{2}\right)$, the snow load $\left(3.5 \mathrm{kN} / \mathrm{m}^{2}\right)$ and the wind load $\left(0.322 \mathrm{kN} / \mathrm{m}^{2}\right)$. The load from 
equipment and live load is applied to the cross structural members of the bottom, which are hinged supported along the perimeter. Snow load is also applied to the hinged supported roof cross members. The obtained cross-sections of the elements, which have been tested for the basic load combinations according to the first and second limit states (ultimate limit state ULS and serviceability limit state - SLS) are shown in Fig. 4 and Table 1. Further these cross-sections of the elements were selected as the basis. Calculation results for the first limit state (ULS) for the basic load combinations are shown in Fig. 5.

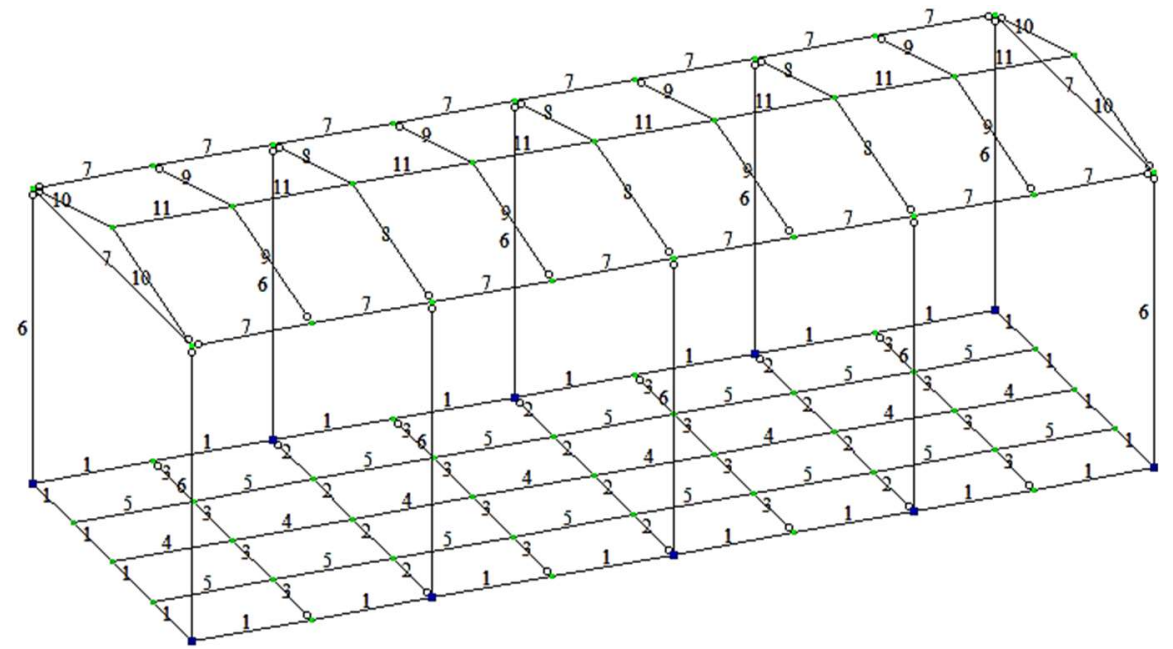

Fig. 4. Numbers of cross-sections of block-box elements.

Table 1.

\begin{tabular}{|c|l|l|l|}
\hline Element № & \multicolumn{1}{|c|}{ Profiletype } & \multicolumn{1}{c|}{ Profile size } & \multicolumn{1}{c|}{ Productmix } \\
\hline $\mathbf{1}$ & Box of channels & № 12 & GOST 8240-97 \\
\hline $\mathbf{2}$ & Box of channels & № 12 & GOST $8240-97$ \\
\hline $\mathbf{3}$ & Channel & № 10 & GOST 8240-97 \\
\hline $\mathbf{4}$ & Box of channels & № 6.5 & GOST $8240-97$ \\
\hline $\mathbf{5}$ & Structural tubing & $40 \times 40 \times 4 \mathrm{~mm}$ & GOST 30245-2012 \\
\hline $\mathbf{6}$ & Structural tubing & $100 \times 100 \times 5 \mathrm{~mm}$ & GOST 30245-2012 \\
\hline $\mathbf{7}$ & Structural tubing & $100 \times 100 \times 5 \mathrm{~mm}$ & GOST 30245-2012 \\
\hline $\mathbf{8}$ & Structural tubing & $100 \times 100 \times 5 \mathrm{~mm}$ & GOST 30245-2012 \\
\hline $\mathbf{9}$ & Structural tubing & $100 \times 50 \times 5 \mathrm{~mm}$ & GOST 30245-2012 \\
\hline $\mathbf{1 0}$ & Structural tubing & $100 \times 40 \times 5 \mathrm{~mm}$ & GOST 30245-2012 \\
\hline $\mathbf{1 1}$ & Structural tubing & $100 \times 100 \times 4 \mathrm{~mm}$ & GOST 30245-2012 \\
\hline
\end{tabular}

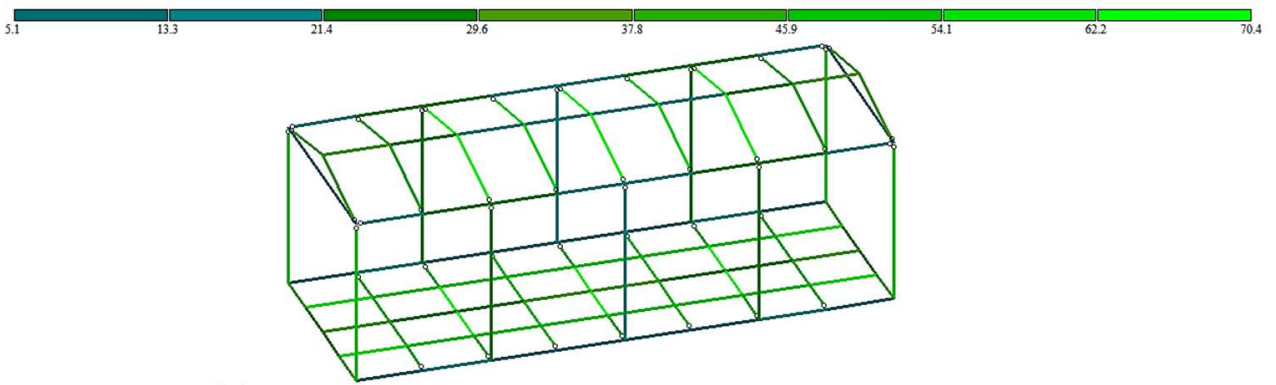

Fig. 5. Calculation results for the ULS (basic load combinations) for the $1^{\text {st }}$ load case. 
The performed calculations showed that the adopted cross-sections satisfy the conditions of strength and stiffness. The load factor of the bearing capacity for the ULS is $\mathrm{k}_{1}=70.4 \%$, for the SLS is $\mathrm{k}_{2}=95.5 \%$. The general weight of the block-box structure for this loading option was $2160 \mathrm{~kg}$ or $77 \mathrm{~kg} / \mathrm{m}^{2}$.

\section{$2.22^{\text {nd }}$ load case}

In this load case the influences of basic load and the special loads (blast wave $-5 \mathrm{kPa}$ ) are considered. The calculation of the explosion loads is carried out in accordance with par. 5.5 [28]. Equivalent static loads from deflagration explosions gas-vapour mixtures, when calculating according to the ULS, are determined using dynamic factor (Fig. 6), where arrows show the direction of spreading of the blast wave.
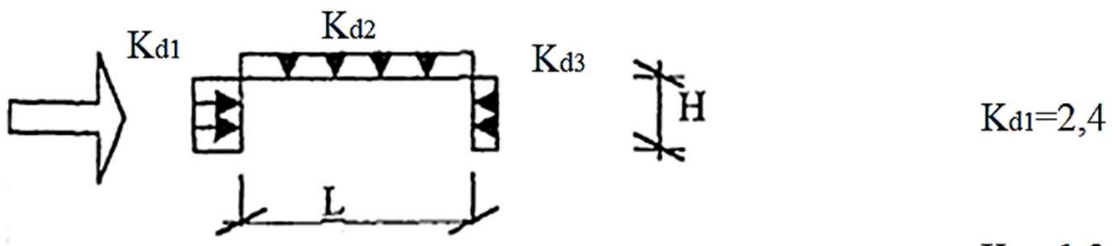

$$
\mathrm{Kd} 2=1,2
$$
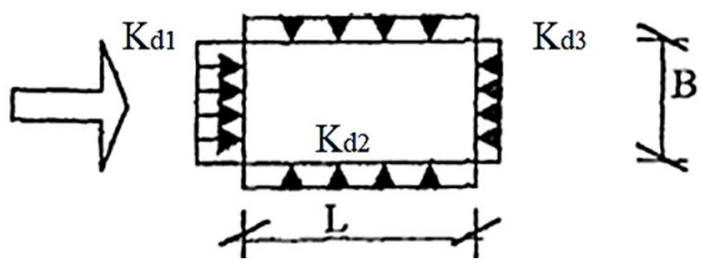

$$
\mathrm{K} d 3=0,6
$$

Fig. 6. Adopted dunamic factors.

According to the Figure 6 most of the blast load is perceived by the face of the wall from the blast side. Therefore, the location of the building on the master plan in relation to the source of the explosion has a great importance.

To compare different version there is an example of the calculation for the ULS of two identical block-boxes with the adopted cross-sections from the $1^{\text {st }}$ loading option, with equal loads, but different front sides (Fig. 7, 8).

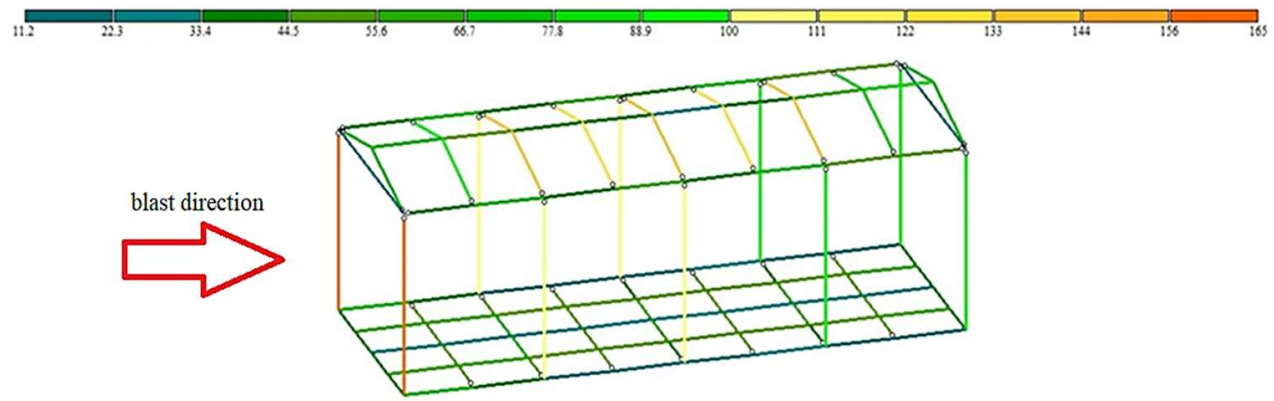

Fig. 7. Calculation results for the blast wave acting from the short side of the block-box for the $2^{\text {nd }}$ load case.

The load factor of the bearing capacity for the ULS is $\mathrm{k}_{1}=165 \%$. 


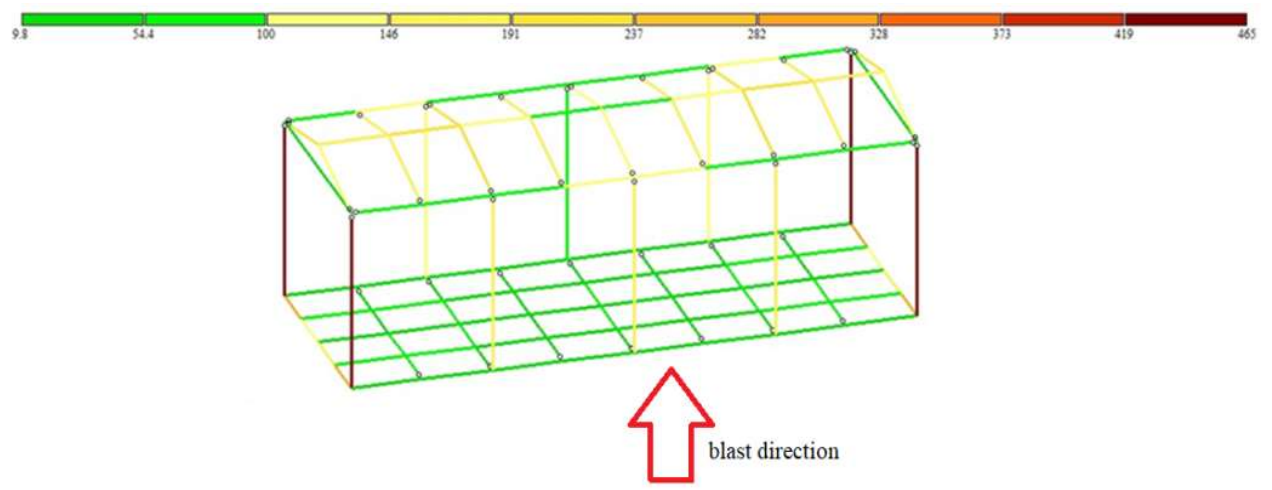

Fig. 8. Calculation results for the blast wave acting from the long side of the block-box for the $2^{\text {nd }}$ load case.

The load factor of the bearing capacity for the ULS was $\mathrm{k}_{1}=465 \%$. The calculation results differ by almost three times. The load factor of the bearing capacity in case of explosion on the short side is $\mathrm{k}_{1}=165 \%$, on the long side $\mathrm{k}_{1}=465 \%$. The difference is equal $281 \%$. For this reason, it is recommended to locate such structures with the smaller side towards the source of the explosion. Moreover, when the larger side is located towards the source of the explosion, it is much more difficult to reinforce the structures of the block-box with vertical ties, due to the frequent placement of door or window openings in this place.

Next, the options for reinforcement of the block-box, which perceives the explosive load from the short front side will be considered, since under this condition a greater stiffness of the structure is achieved and the metal consumption is significantly reduced.

\section{$2.31^{\text {st }}$ reinforcement version}

Reinforcement is implemented by increasing the cross-section of the elements. The resulting cross-section of the elements is shown in Fig. 9 and Table 2. The mosaic of the calculation results for the ULS is shown in Fig. 10.

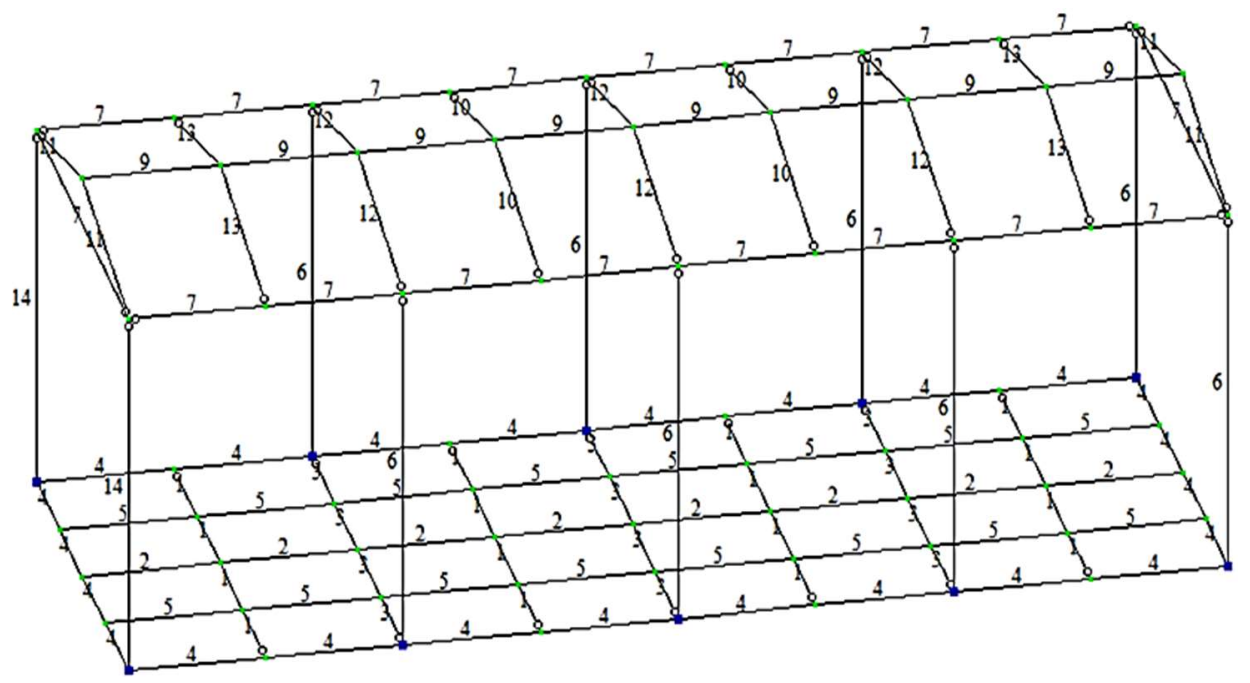

Fig. 9. $1^{\text {st }}$ reinforcement version by increasing the cross-section of the elements. 
Table 2.

\begin{tabular}{|c|l|l|l|}
\hline Element № & Profiletype & Profile size & Productmix \\
\hline $\mathbf{1}$ & Channel & № 10 & GOST 8240-97 \\
\hline $\mathbf{2}$ & Box of channels & № 6.5 & GOST $8240-97$ \\
\hline $\mathbf{3}$ & Box of channels & № 12 & GOST $8240-97$ \\
\hline $\mathbf{4}$ & Box of channels & № 16 & GOST $8240-97$ \\
\hline $\mathbf{5}$ & Structural tubing & $40 \times 40 \times 4 \mathrm{~mm}$ & GOST 30245-2012 \\
\hline $\mathbf{6}$ & Structural tubing & $100 \times 100 \times 5 \mathrm{~mm}$ & GOST 30245-2012 \\
\hline $\mathbf{7}$ & Structural tubing & $100 \times 100 \times 5 \mathrm{~mm}$ & GOST 30245-2012 \\
\hline $\mathbf{8}$ & Structural tubing & $100 \times 100 \times 5 \mathrm{~mm}$ & GOST 30245-2012 \\
\hline $\mathbf{9}$ & Structural tubing & $100 \times 100 \times 4 \mathrm{~mm}$ & GOST 30245-2012 \\
\hline $\mathbf{1 0}$ & Structural tubing & $100 \times 100 \times 5 \mathrm{~mm}$ & GOST 30245-2012 \\
\hline $\mathbf{1 1}$ & Structural tubing & $100 \times 40 \times 5 \mathrm{~mm}$ & GOST 30245-2012 \\
\hline $\mathbf{1 2}$ & Structural tubing & $100 \times 100 \times 8 \mathrm{~mm}$ & GOST 30245-2012 \\
\hline $\mathbf{1 3}$ & Structural tubing & $100 \times 60 \times 6 \mathrm{~mm}$ & GOST 30245-2012 \\
\hline $\mathbf{1 4}$ & Structural tubing & $120 \times 120 \times 7 \mathrm{~mm}$ & GOST 30245-2012 \\
\hline
\end{tabular}

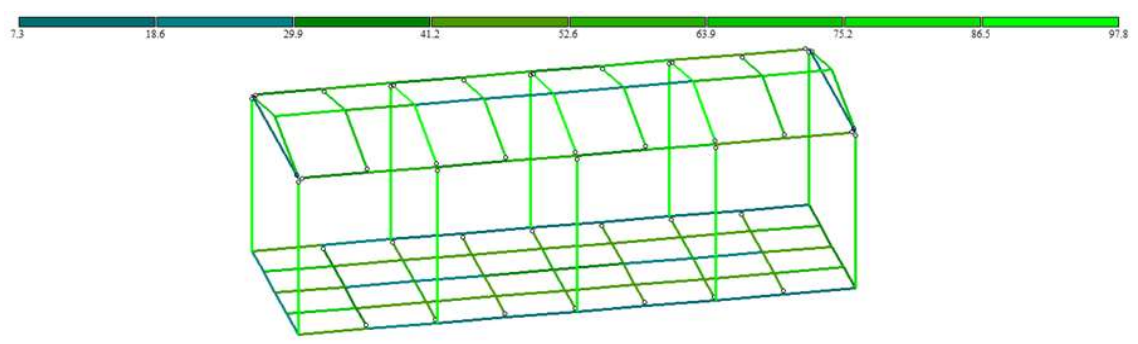

Fig. 10. Calculation results for the ULS for the 1 st reinforcement version.

The performed calculations showed that the adopted cross-sections satisfy the strength conditions. The load factor of the bearing capacity for the ULS is $\mathrm{k}_{1}=97.8 \%$.

The general weight of the block-box structure for such reinforcement version is $2500 \mathrm{~kg}$ or $89 \mathrm{~kg} / \mathrm{m}^{2}$.

\section{$2.42^{\text {nd }}$ reinforcement version}

In this scenario the reinforcement is implemented by installing vertical, horizontal ties and increasing the cross-section of the elements. The resulting cross-section of the elements is shown in Fig. 11 and Table 3. The mosaic of the calculation results for the ULS is shown in Fig. 12.

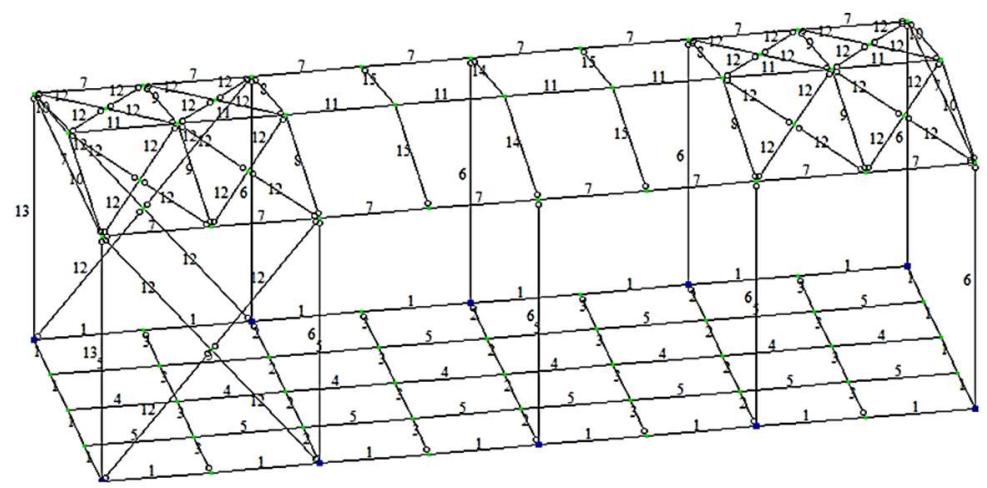

Fig. 11. $2^{\text {nd }}$ reinforcement version by installing vertical, horizontal ties. 
Table 3.

\begin{tabular}{|c|l|l|l|}
\hline Element № & Profile type & Profile size & Product mix \\
\hline $\mathbf{1}$ & Box of channels & № 12 & GOST $8240-97$ \\
\hline $\mathbf{2}$ & Box of channels & № 12 & GOST $8240-97$ \\
\hline $\mathbf{3}$ & Channel & № 10 & GOST $8240-97$ \\
\hline $\mathbf{4}$ & Box of channels & № 6.5 & GOST $8240-97$ \\
\hline $\mathbf{5}$ & Structural tubing & $40 \times 40 \times 4 \mathrm{~mm}$ & GOST 30245-2012 \\
\hline $\mathbf{6}$ & Structural tubing & $100 \times 100 \times 5 \mathrm{~mm}$ & GOST 30245-2012 \\
\hline $\mathbf{7}$ & Structural tubing & $100 \times 100 \times 5 \mathrm{~mm}$ & GOST 30245-2012 \\
\hline $\mathbf{8}$ & Structural tubing & $100 \times 100 \times 5 \mathrm{~mm}$ & GOST 30245-2012 \\
\hline $\mathbf{9}$ & Structural tubing & $100 \times 50 \times 5 \mathrm{~mm}$ & GOST 30245-2012 \\
\hline $\mathbf{1 0}$ & Structural tubing & $100 \times 40 \times 5 \mathrm{~mm}$ & GOST 30245-2012 \\
\hline $\mathbf{1 1}$ & Structural tubing & $100 \times 100 \times 4 \mathrm{~mm}$ & GOST 30245-2012 \\
\hline $\mathbf{1 2}$ & Angle & $50 \times 50 \times 5 \mathrm{~mm}$ & GOST $8509-93$ \\
\hline $\mathbf{1 3}$ & Structural tubing & $200 \times 100 \times 4 \mathrm{~mm}$ & GOST 30245-2012 \\
\hline $\mathbf{1 4}$ & Structural tubing & $100 \times 100 \times 8 \mathrm{~mm}$ & GOST 30245-2012 \\
\hline $\mathbf{1 5}$ & Structural tubing & $100 \times 50 \times 7 \mathrm{~mm}$ & GOST 30245-2012 \\
\hline
\end{tabular}
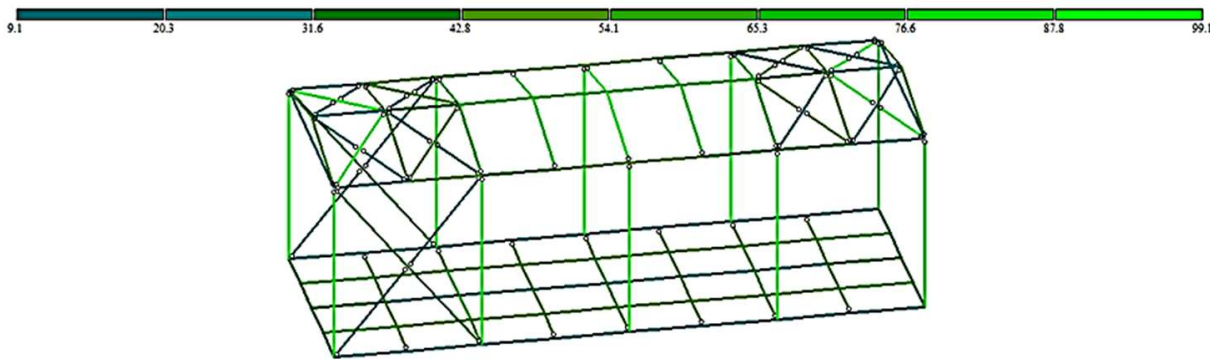

Fig. 12. Calculation results for the ULS for the $2^{\text {nd }}$ reinforcement version.

The performed calculations showed that the adopted cross-sections satisfy the strength conditions. The load factor of the bearing capacity for the ULS is $\mathrm{k}_{1}=99.1 \%$.

The general weight of the block-box structure for such reinforcement version is $2392 \mathrm{~kg}$ or $85 \mathrm{~kg} / \mathrm{m}^{2}$.

\section{$2.53^{\text {rd }}$ load case}

Now the influence of the basic and seismic loads is considered. The technological block-box is planned to be operated in a region with a seismic activity of 7 points. The parameters of the calculation for seismic impact are presented in Fig. 13.

$\mathrm{X}$-axis

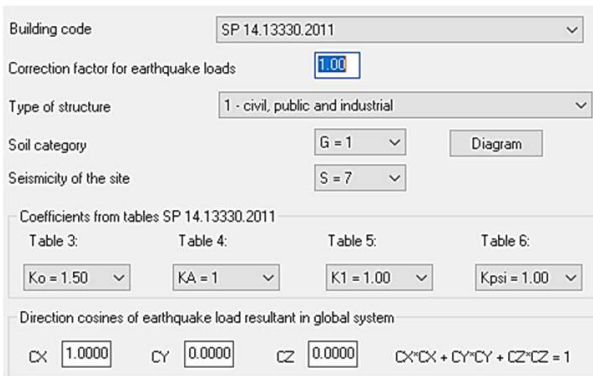

Y-axis

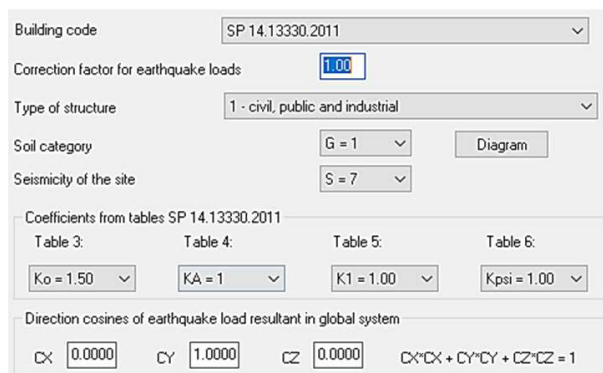

Fig. 13. Parameters of the calculation for seismic impact. 
Coefficients $K_{0}, K_{1}, K_{\text {psi }}$ are taken according to tables 3, 5, 6 from the standard SP 14.13330. $\mathrm{K}_{0}$ is taken equal to 1.5 , since the technological block-box is a structure with a higher level of responsibility. Damage or inelastic deformation should not be allowed in the block-box, as this can harm the equipment inside the box, therefore $K_{1}=1$. The coefficient which takes into account the ability of the building to dissipate energy is $K_{p s i}=1$.

The mass of the block-box structure for seismic load is collected from its dead load, equipment and snow loads.

A mosaic of the calculation results for the ULS from the basic and seismic loads is shown in Fig. 14.

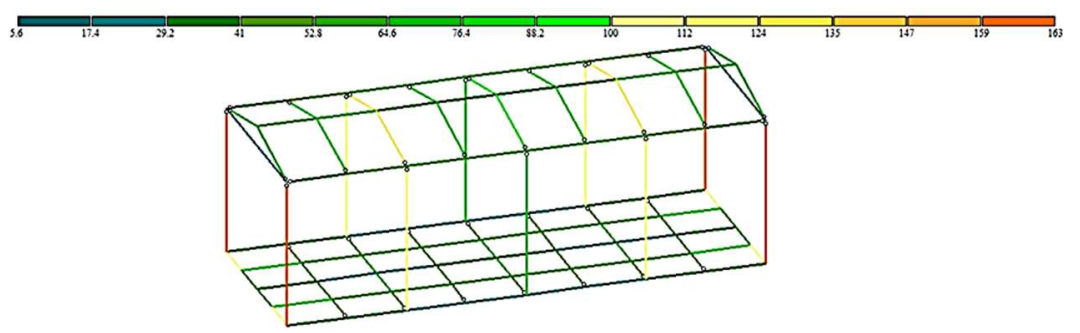

Fig. 14. Calculation results for the ULSfrom the basic and seismic loads for the $3^{\text {rd }}$ load case.

The load factor for the ULS was $\mathrm{k} 1=163 \%$.

\section{$2.61^{\text {st }}$ reinforcement version}

Reinforcement is implemented by increasing the cross-section of the elements. The resulting cross-section of the elements is shown in Fig. 15 and Table 4. The mosaic of the calculation results for the ULS is shown in Fig. 16.

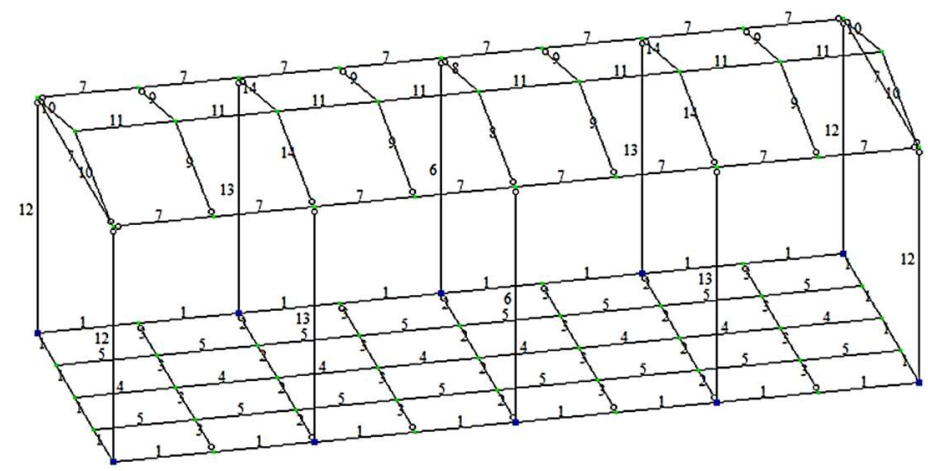

Fig. 15. $1^{\text {st }}$ reinforcement version by increasing the cross-section of the elements the $3^{\text {rd }}$ load case.

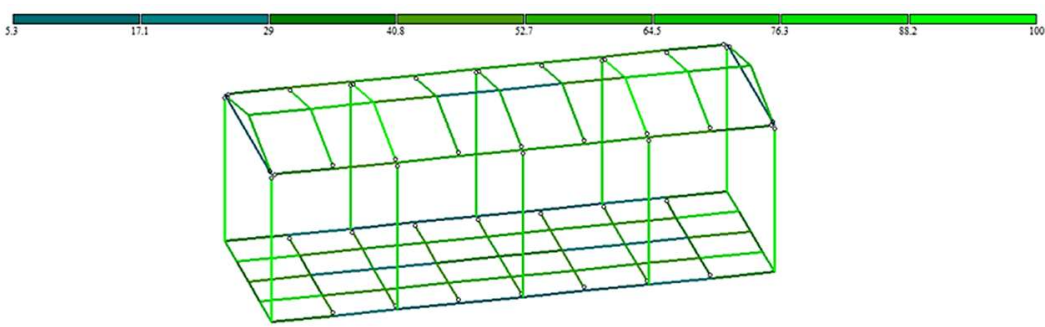

Fig. 16. Calculation results for the ULS for the $3^{\text {rd }}$ load case, $1^{\text {st }}$ reinforcement version. 
Table 4.

\begin{tabular}{|c|l|l|l|}
\hline Element № & Profiletype & Profile size & Productmix \\
\hline $\mathbf{1}$ & Box of channels & № 16 & GOST 8240-97 \\
\hline $\mathbf{2}$ & Box of channels & № 12 & GOST 8240-97 \\
\hline $\mathbf{3}$ & Channel & № 10 & GOST 8240-97 \\
\hline $\mathbf{4}$ & Box of channels & № 6.5 & GOST $8240-97$ \\
\hline $\mathbf{5}$ & Structural tubing & $40 \times 40 \times 4 \mathrm{~mm}$ & GOST 30245-2012 \\
\hline $\mathbf{6}$ & Structural tubing & $100 \times 100 \times 6 \mathrm{~mm}$ & GOST 30245-2012 \\
\hline $\mathbf{7}$ & Structural tubing & $100 \times 100 \times 5 \mathrm{~mm}$ & GOST 30245-2012 \\
\hline $\mathbf{8}$ & Structural tubing & $100 \times 100 \times 5 \mathrm{~mm}$ & GOST 30245-2012 \\
\hline $\mathbf{9}$ & Structural tubing & $100 \times 60 \times 6 \mathrm{~mm}$ & GOST 30245-2012 \\
\hline $\mathbf{1 0}$ & Structural tubing & $100 \times 40 \times 5 \mathrm{~mm}$ & GOST 30245-2012 \\
\hline $\mathbf{1 1}$ & Structural tubing & $100 \times 100 \times 4 \mathrm{~mm}$ & GOST 30245-2012 \\
\hline $\mathbf{1 2}$ & Structural tubing & $120 \times 120 \times 8 \mathrm{~mm}$ & GOST 30245-2012 \\
\hline $\mathbf{1 3}$ & Structural tubing & $100 \times 100 \times 7 \mathrm{~mm}$ & GOST 30245-2012 \\
\hline $\mathbf{1 4}$ & Structural tubing & $100 \times 100 \times 8 \mathrm{~mm}$ & GOST 30245-2012 \\
\hline
\end{tabular}

So, the performed calculations showed that the adopted cross-sections satisfy the strength conditions. The load factor of the bearing capacity for the ULS is $\mathrm{k}_{1}=99.9 \%$.

The general weight of the block-box structure for such reinforcement version is $2610 \mathrm{~kg}$ or $93 \mathrm{~kg} / \mathrm{m}^{2}$.

\section{$2.72^{\text {nd }}$ reinforcement version}

In this version the reinforcement is implemented by installing vertical, horizontal ties and increasing the cross-section of the elements. The resulting cross-section of the elements is shown in Fig. 17 and Table 5. The mosaic of the calculation results for the ULS is shown in Fig. 18.

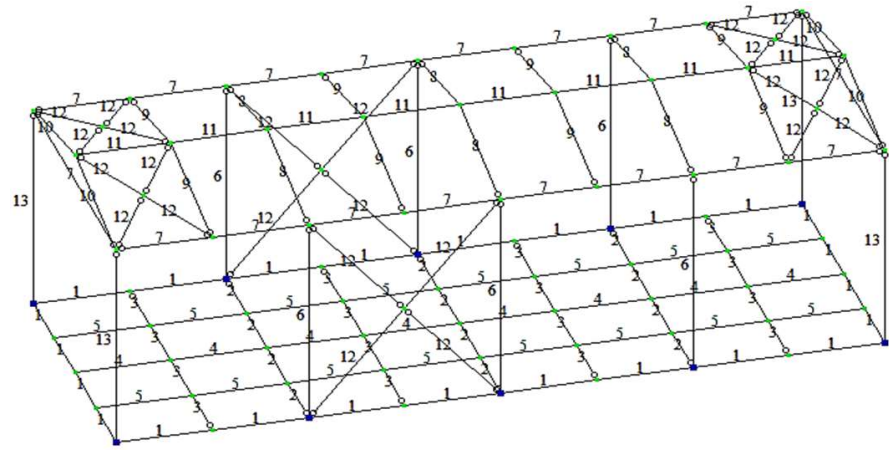

Fig. 17. $2^{\text {nd }}$ reinforcement version by installing vertical, horizontal ties and increasing the cross-section of the elements for the $3^{\text {rd }}$ load case.

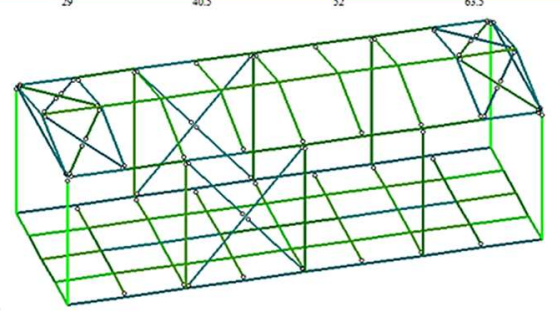

Fig. 18. Calculation results for the ULS for the $3^{\text {rd }}$ load case, $1^{\text {st }}$ reinforcement version. 
Table 5.

\begin{tabular}{|c|l|l|l|}
\hline Element № & Profiletype & Profile size & Productmix \\
\hline $\mathbf{1}$ & Box of channels & № 16 & GOST $8240-97$ \\
\hline $\mathbf{2}$ & Box of channels & № 12 & GOST $8240-97$ \\
\hline $\mathbf{3}$ & Channel & № 10 & GOST $8240-97$ \\
\hline $\mathbf{4}$ & Box of channels & № 6.5 & GOST $8240-97$ \\
\hline $\mathbf{5}$ & Structural tubing & $40 \times 40 \times 4 \mathrm{~mm}$ & GOST 30245-2012 \\
\hline $\mathbf{6}$ & Structural tubing & $100 \times 100 \times 5 \mathrm{~mm}$ & GOST 30245-2012 \\
\hline $\mathbf{7}$ & Structural tubing & $100 \times 100 \times 5 \mathrm{~mm}$ & GOST 30245-2012 \\
\hline $\mathbf{8}$ & Structural tubing & $100 \times 100 \times 5 \mathrm{~mm}$ & GOST 30245-2012 \\
\hline $\mathbf{9}$ & Structural tubing & $100 \times 50 \times 5 \mathrm{~mm}$ & GOST 30245-2012 \\
\hline $\mathbf{1 0}$ & Structural tubing & $100 \times 40 \times 5 \mathrm{~mm}$ & GOST 30245-2012 \\
\hline $\mathbf{1 1}$ & Structural tubing & $100 \times 100 \times 4 \mathrm{~mm}$ & GOST 30245-2012 \\
\hline $\mathbf{1 2}$ & Angle & $50 \times 50 \times 5 \mathrm{~mm}$ & GOST 30245-2012 \\
\hline $\mathbf{1 3}$ & Structural tubing & $120 \times 120 \times 6 \mathrm{~mm}$ & GOST 30245-2012 \\
\hline
\end{tabular}

The performed calculations showed that the adopted cross-sections satisfy the strength conditions. The load factor of the bearing capacity for the ULS is $\mathrm{k}_{1}=98 \%$.

The general weight of the block-box structure for such reinforcement version is $2515 \mathrm{~kg}$ or $90 \mathrm{~kg} / \mathrm{m}^{2}$.

\section{Results and discussion}

The results obtained for all load cases and reinforcement versions are represented in Table 6 and fig. 19, 20.

Table 6.

\begin{tabular}{|c|c|c|c|c|c|}
\hline $\begin{array}{l}\text { № of } \\
\text { case }\end{array}$ & \multicolumn{2}{|c|}{$\begin{array}{l}\text { Load/ } \\
\text { reinforcement }\end{array}$} & $\begin{array}{l}\text { Load factor of the } \\
\text { bearing capacity } \\
\text { for the ULS, \% }\end{array}$ & $\begin{array}{c}\text { General } \\
\text { weight, kg }\end{array}$ & $\begin{array}{l}\text { Steel spread, } \\
\mathrm{kg} / \mathrm{m}^{2}\end{array}$ \\
\hline 1 & \multicolumn{2}{|c|}{$1^{\text {st }}$ load case } & 70.4 & 2160.0 & 77.0 \\
\hline 2 & \multirow{2}{*}{$2^{\text {nd }}$ load case } & $1^{\text {st }}$ reinf & 97.8 & 2500.0 & 89.0 \\
\hline 3 & & $2^{\text {nd }}$ reinf & 99.1 & 2392.0 & 85.0 \\
\hline 4 & \multirow{2}{*}{$3^{\text {rd }}$ load case } & $1^{\text {st }}$ reinf & 99.9 & 2610.0 & 93.0 \\
\hline 5 & & $2^{\text {nd }}$ reinf & 98.0 & 2515.0 & 90.0 \\
\hline
\end{tabular}

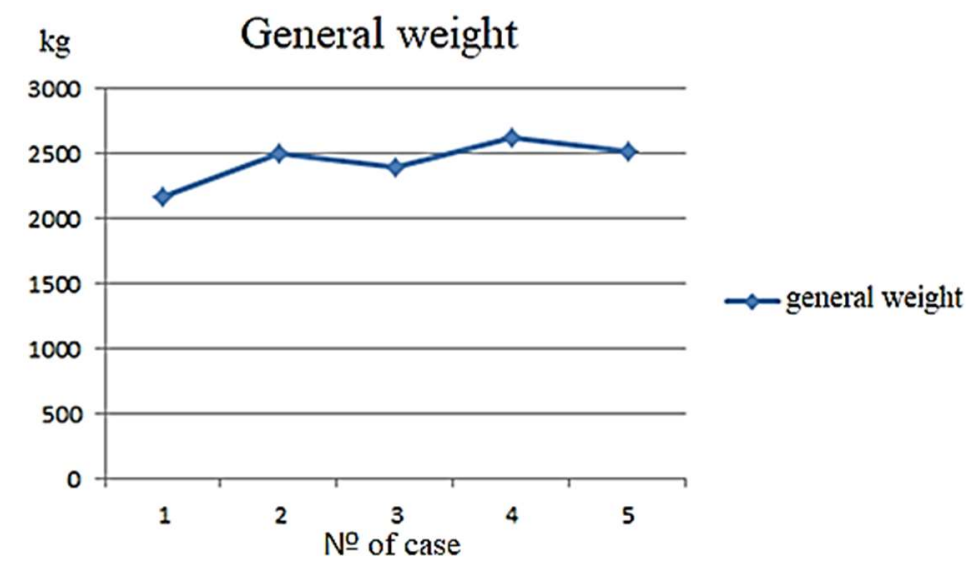

Fig. 19. General weight diagram. 


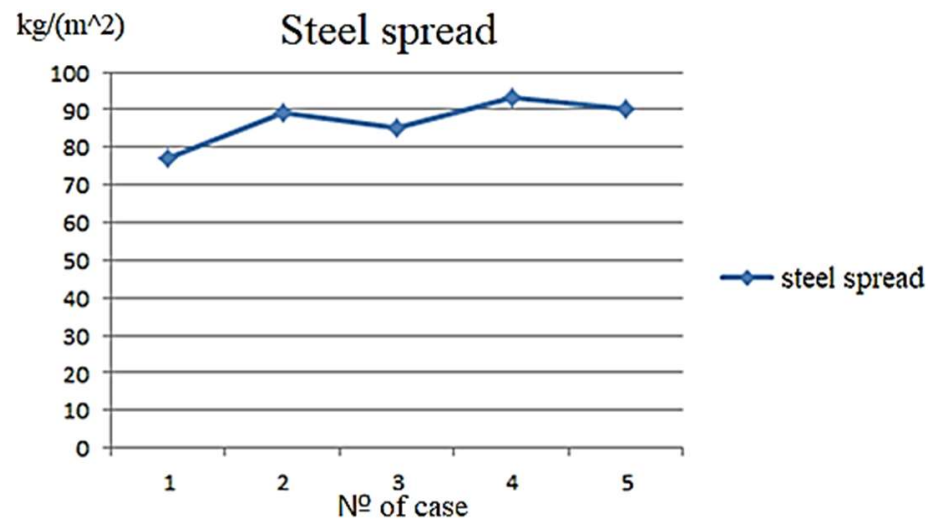

Fig. 20. Steel spread diagram.

The most effective case of reinforcing is increasing the cross-section of the elements and using bracing system. The difference in reinforcement, in terms of steel spread, was 3-4 $\mathrm{kg} / \mathrm{m}^{2}$. The difference in reinforcements, in terms of the general weight of the structure, was $108 \mathrm{~kg}$ and $95 \mathrm{~kg}$.

\section{Conclusions}

1. According to the results of calculations for the 1st load version the general weight of the structure was $2157 \mathrm{~kg}\left(77 \mathrm{~kg} / \mathrm{m}^{2}\right)$. In this case, the load factors of the bearing capacity of the structure were: for the ULS $\mathrm{k}_{1}=70.4 \%$, for the SLS $\mathrm{k}_{2}=95.5 \%$.

2. It was found that the orientation of the block-box along the short or long side with respect to the direction of the explosion wave is essential. The difference is equal $281 \%$. It is recommended to install block-box structures in the direction of the explosion with the short front side.

3 . According to the results of calculations for the 2 nd load version the general weight of the structure was $2392 \mathrm{~kg}\left(85 \mathrm{~kg} / \mathrm{m}^{2}\right)$. Reinforcement by installing a bracing system and increasing the cross-section was found to be more effective by $4.5 \%$. At the same time, the load factor of the bearing capacity for the ULS was $\mathrm{k}_{1}=99.1 \%$.

4. According to the results of calculations for the $3 \mathrm{rd}$ load version the general weight of the structure was $2515 \mathrm{~kg}\left(90 \mathrm{~kg} / \mathrm{m}^{2}\right)$. Reinforcement by installing a bracing system and increasing the cross-section was found to be more effective by $3.7 \%$. At the same time, the load factor of the bearing capacity for the ULS was $\mathrm{k}_{1}=98 \%$.

\section{References}

1. R.M. Lawson et al. Developments in pre-fabricated systems in light steel and modular construction, Structural Engineer 83 6, 28-35 (2005).

2. L. Jaillon, C.S. Poon The evolution of prefabricated residential building systems in Hong Kong: A review of the public and the private sector, Automation in Construction 183 , 239-248 (2009).

3. R.K. Mukhametrakhimov, L.V. Lukmanova. Structure and properties of mortar printed on a 3D-printer, Mag. Civ. Eng. 102 2, 10206 (2021).

4. R. Mukhametrakhimov, L. Lukmanova. Influence of the technological properties of cement-sand mortar on the quality of 3D-printed products, IOP Conference Series: Materials Science and Engineering 890 1, (2020).

5. R.Kh. Mukhametrakhimov. V.I.M. Additive technology of erection of buildings and structures using building 3D-printer, Izv. KGASU 4 42, 350-359 (2017). 
6. W. Ferdous et al. New advancements, challenges and opportunities of multi-storey modular buildings - A state-of-the-art review, Engineering Structures 183, 883-893 (2019).

7. J.P. Hao et al. Research and applications of prefabricated steel structure building systems, Gongcheng Lixue/Engineering Mechanics. Tsinghua University 34 1, 1-13 (2017).

8. I.P. Kozhushkov, A.P. Smirnov, K.V. Kolonskikh. Perspective Block-Modular Methods for the Construction of Oil and Gas Facilities Using Superblocks, PROneft'. Proffessional'no o Nefti 2, 71-75 (2019). DOI: 10.24887/2587-7399-2019-2-71-75.

9. A.G. Ogydov, L.I. Andrianova, A.P. Pneva. Implementation of an industrial construction method using units of maximum factory readiness, Materials of the International Scientific and Technical Conference dedicated to the $50^{\text {th }}$ anniversary of the Tyumen Industrial Institute, 121-123 (2013).

10. M. Zakharova, A. Ponomarev. Experience in Constructing Buildings and Structures Using Modular Technology, PNRPU Construction and Architecture Bulletin 8 (1), 148155 (2017). DOI: 10.15593/2224-9826/2017.1.13.

11. V.L. Sel'chenkov. Typical technical solutions for ventilation and climate control systems for GIS block-boxes, Industrial automation 10, 48-50 (2009).

12. M.Ju. Jakovlev. Analysis of the impact of explosive loads on the elements of an industrial building, Topical issues of modern science: Collection of articles based on the materials of the VIII international scientific and practical conference, 33-37 (2017).

13. B.S. Rastorguev, A.I. Plotnikov, D.Z. Husnutdinov. Design of buildings and structures under emergency explosive effects: a tutorial 152, (2007).

14. L. Figuli, D. Cekerevac, C. Bedon, B. Leitner. Numerical analysis of the blast wave propagation due to various explosive charges, Advances in Civil Engineering 2020(i), (2020). DOI: 10.1155/2020/8871412.

15. K. Singh, P. Gardoni, F. Stochino. Probabilistic models for blast parameters and fragility estimates of steel columns subject to blast loads, Engineering Structures 222 (April), 110944 (2020). DOI: 10.1016/j.engstruct.2020.110944.

A. Ju. Sorokin. Universal approach to simulation of explosive loads on infrastructure objects of any type, Safety and labor protection, youth program within the framework of the International Exhibition, 170-173 (2019).

16. M.N. Kochepanova, V.D. Bosov. Experience in determining the explosive load using modern software systems and calculation methods, Modern technologies in construction. Theory and practice 1, 134-140 (2017).

17. V.P. Avdot'in, A.V. Akin'shin, Ju.B. Andreev. Natural hazards of Russia: monograph in 6 volumes $248,(2002)$.

18. A. Flora, D. Cardone, M. Vona, G. Perrone. A Simplified Approach for the Seismic Loss Assessment of RC Buildings at Urban Scale: The Case Study of Potenza (Italy), Buildings 11 (4), 142 (2021). DOI: 10.3390/buildings1104014.

19. M.V. Ashirova, G.N. Ajdarova. Rapid response architecture: the concept of temporary mobile shelter in emergencies, Izvestia of Kazan State University of Architecture and Civil Engineering 2 (36), 17-22 (2016).

20. D.V. Malysheva, A.O. Malyshev. Arrangement of well pad for oil field, Matrix of scientific knowledge 12-2, 349-353 (2020).

21. T.G. Korotkova, K.S. Bozhenova. Statistics and causes of accidents at facilities oil and gas production, Scientific works of KubGTU 1, 115-127 (2019).

22. OST 26.260.18-2004. Technological units for gas and oil industry. General specifications.

23. V.S. Shirokov, I.S. Holopov, A.V. Solov'ev. Calculation of a modular building, assembled from block boxes, Tradition and innovation in construction and architecture. Construction: a collection of articles, 84-89 (2015). 
24. I.S. Holopov, V.S. Shirokov, A.V. Solov'ev, Ju.D. Makarov. Analysis of the stress-strain state of a pre-fabricated modular building, Industrial and civil construction 6, 15-19 (2015).

25. V.S. Shirokov, A.V. Solov'ev, I.S. Holopov. Taking into account the pulsating wind load when calculating a production modular building, Tradition and innovation in construction and architecture, 18-21 (2016).

26. V.V. Korolev, N.A. Klekovkina. Calculation of buildings and structures on the progressive collapse due to an emergency, Implementation of modern designs and advanced technologies in the track facilities 12 (12), 155-157 (2018).

27. Manual for the survey and design of buildings and structures exposed to explosive loads, JSC «TsNIIPromzdaniy», (2020). 